\title{
Asymmetric Synthesis of Secondary Alcohols and 1,2-Disubstituted Epoxides via Organocatalytic Sulfenylation
}

\author{
Filippo Rotaa,1 \\ Laure Benhamoua \\ Tom D. Sheppard*a \\ ${ }^{a}$ Department of Chemistry, Christropher Ingold Laboratories, \\ 20 Gordon St, London, WC1H OAJ, UK \\ * indicates the main/corresponding author.
}

\section{tom.sheppard@ucl.ac.uk}

Dedicated to Professor Steven V. Ley CBE FRS; Happy $70^{\text {th }} B^{\prime}$ DA-y Steve!

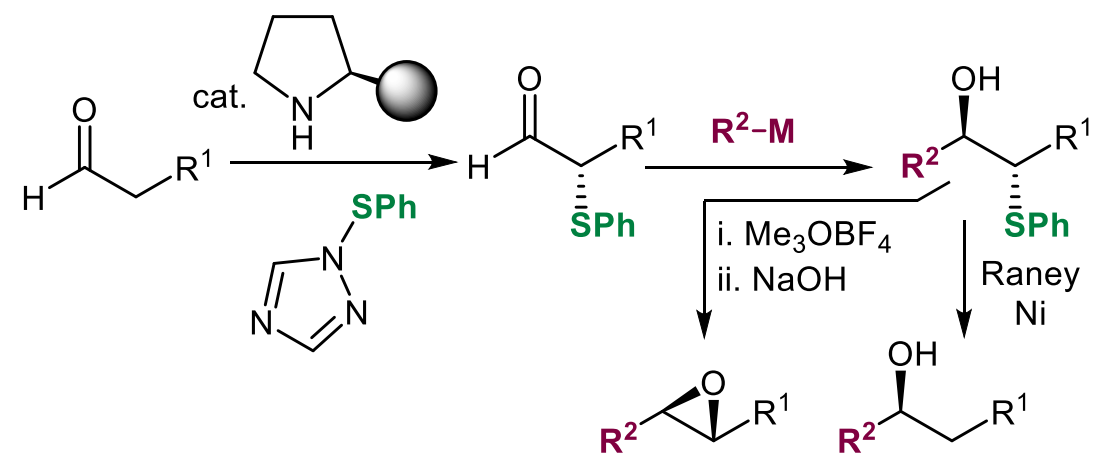

The field of organocatalysis has grown enormously over the past 20 years, with many effective methods now available for carrying out asymmetric reactions using small molecule catalysts. ${ }^{4}$ In particular, many different catalysts derived from amino acids have been developed for achieving asymmetric functionalisation of aldehydes via 'enamine' catalysis. ${ }^{5}$ The Jørgensen-Hayashi catalyst $2^{6}$ has proved to be particularly versatile in this respect as it can be used to introduce a wide variety of groups at the alpha position of an aldehyde with high levels of asymmetric induction in most cases. ${ }^{6-8}$ Organocatalytic sulfenylation reactions have been reported using $N$-sulfenylheterocycles as electrophiles, although to date only the synthesis of benzyl ${ }^{8 a}$ and hexyl ${ }^{8 b, 8 c}$ sulfides has been reported.

The choice of sulfur group for our proposed asymmetric synthesis of secondary alcohols is crucial as a high diastereoselectivity in the organometallic addition reaction is a pre-requisite for an efficient synthesis. From a study of the literature ${ }^{9}$ and preliminary experiments we noted that higher diastereoselectivities were obtained from addition of organometallic reagents to aldehydes bearing bulkier groups such as tert-butyl or phenyl sulfides. The latter group was selected for further exploration, due to the extremely potent odor of tert-butyl thiol and its derivatives. As to the best of our knowledge the asymmetric introduction of a phenylsulfenyl group $^{9 \mathrm{~d}}$ has never been previously reported using organocatalysis, we began our investigation by preparing the requisite $N$-phenylsulfenyl triazole $\mathbf{3 a} .^{10}$ With this compound in hand, we were then able to identify a procedure for organocatalytic sulfenylation $^{8}$ to provide the desired $\alpha$-phenylsulfenyl aldehydes in high enantiopurity (Scheme 2). As noted previously, ${ }^{8}$ the $\alpha$-sulfenylaldehydes were prone to partial racemization during chromatographic purification. As can be seen from the measured enantiopurities, even brief exposure of the aldehydes to silica gel can cause some racemization. ${ }^{11}$ 


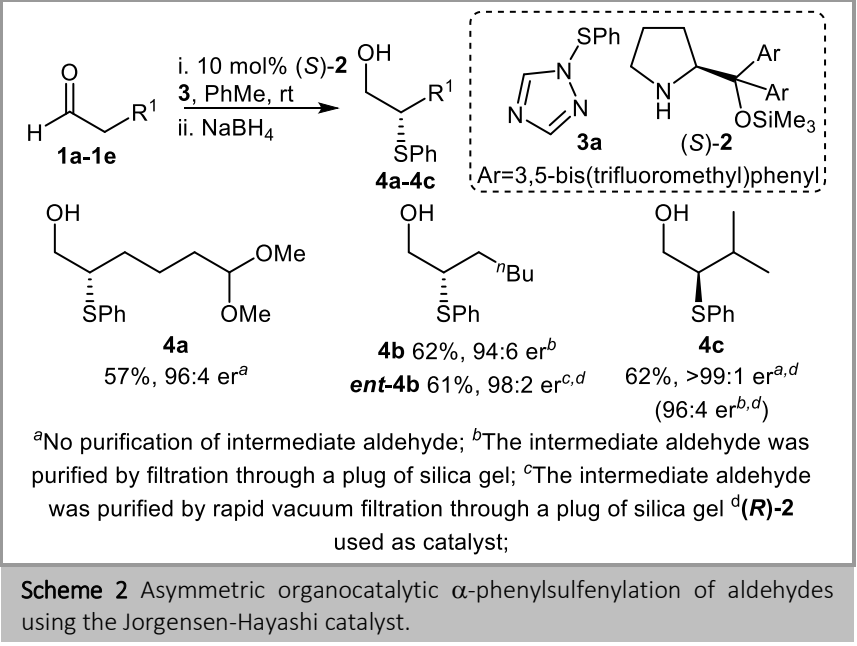

Direct addition of an organometallic reagent to the crude reaction mixture obtained from the asymmetric sulfenylation reaction typically resulted in low yields of the resulting $\beta$-hydroxysulfide and low diastereoselectivity, so a two-step procedure was developed in which the intermediate $\alpha$-sulfenylaldehyde was purified by vacuum filtration through a plug of silica gel, eluting with toluene. ${ }^{12}$ The crude toluene solution of aldehyde was then directly reacted with the required organometallic reagent. This typically resulted in moderate to high yields of the desired $\beta$-hydroxysulfides $\mathbf{5}$ and excellent diastereoselectivity in most cases.

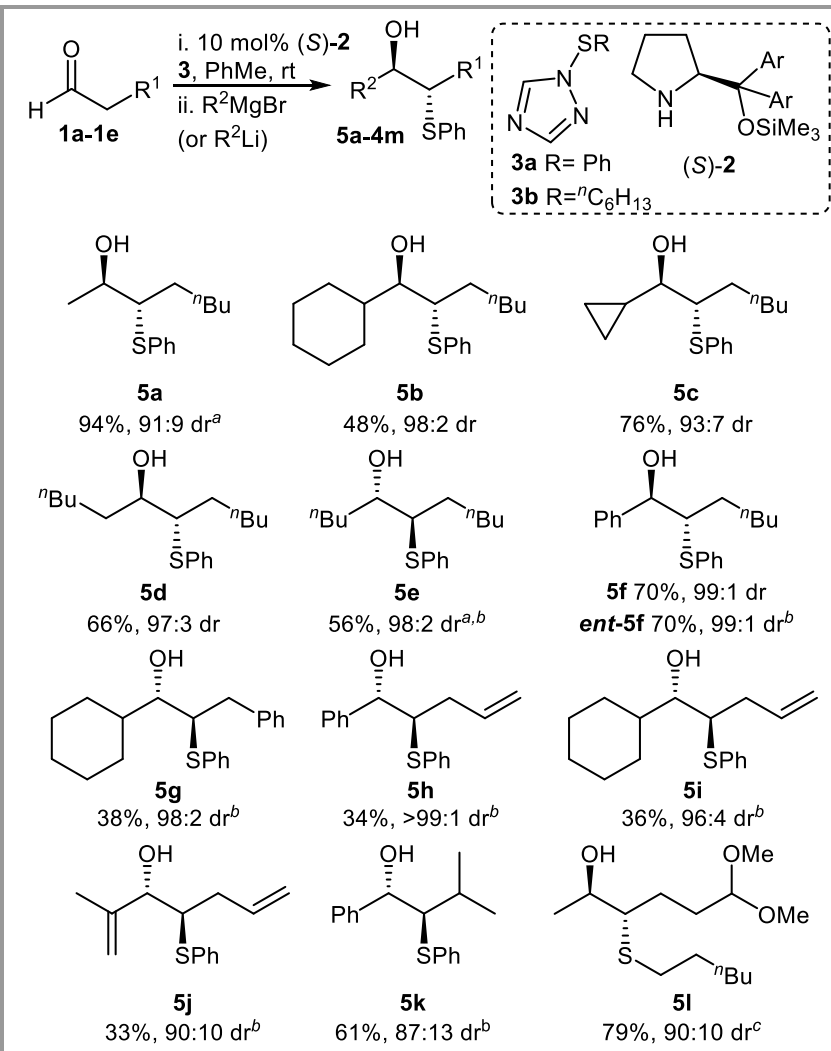

${ }^{a} R^{2}$ Li was used; ${ }^{b}(R)-2$ used as catalyst; ${ }^{c} 3 b$ was used

Scheme 3 Synthesis of $\beta$-hydroxysulfides via organocatalyitc sulfenylation of aldehydes followed by organometallic addition.
The major diastereoisomer was found to be the antidiastereoisomer in accordance with previous reports. $9,13 \mathrm{~A}$ selection of $\beta$-hydroxysulfides 5a-5l was prepared (Scheme 3), including examples containing linear and branched alkyl groups (5a-5e, 5k), benzene rings (5f-5h, 5k), alkenes (5h-5j) and an acetal (5l). With a selection of $\beta$-hydroxysulfides in hand, the key desulfurization step was explored. We had some concerns about the desulfurization as similar transformations of sugarderived sulfides containing free alcohols have been reported to be low yielding. ${ }^{14}$ Pleasingly, however, treatment of a small selection of $\beta$-hydroxysulfides 5a-5d with Raney-nickel in ethanol, resulted in clean desulfurization to give the desired alcohols 6a-6d in generally excellent yield in most cases (Scheme 4). ${ }^{15}$ This provided access to enantioenriched secondary alcohols, including examples which would be extremely difficult to prepare using existing methods (e.g. 6d), due to the very similar steric demands of the groups attached to the alcohol carbon atom. The enantiopurity of the secondary alcohols, as measured using Mosher's acid, ${ }^{11}$ was in close agreement with the calculated enantiopurity ${ }^{16}$ suggesting that only low levels of racemization took place during the reaction sequence. However, in the case of alcohol $\mathbf{6 d}$, it was not possible to determine the enantiomeric ratio directly as the two Mosher's ester derivatives had identical NMR spectra. ${ }^{17}$

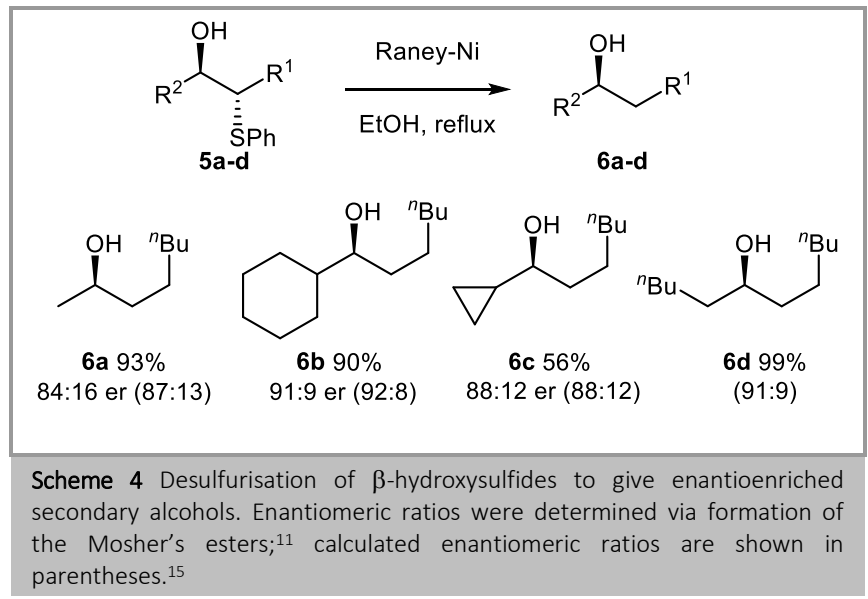

We envisaged that the $\beta$-hydroxysulfides could also be used to synthesise 1,2-disubstituted epoxides via conversion of the sulfide group into a suitable leaving group. ${ }^{18}$ For $\beta$ hydroxysulfide ent-5f this was achieved via alkylation with Meerwein's salt, followed by treatment with base to give the epoxide $\mathbf{7 f}$ in moderate yield. There are relatively few methods available for accessing this type of unfunctionalised 1,2disubstituted epoxide ${ }^{19}$ in high enantiopurity, so this approach may prove extremely useful.

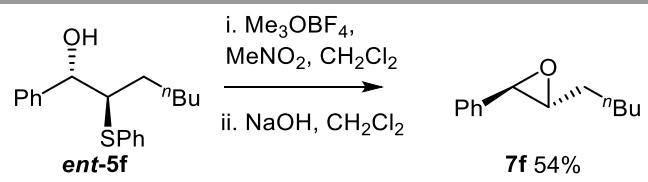

Scheme 5 Conversion of a $\beta$-hydroxysulfide into an enantioenriched 1,2 disubstituted epoxide

In conclusion, we have demonstrated that asymmetric organocatalytic sulfenylation of aldehydes can be employed in 
the synthesis of enantioenriched secondary alcohols and 1,2disubstituted epoxides via short synthetic routes. This approach can provide access to enantiomerically enriched chiral building blocks which are difficult to access via existing approaches.

\section{Acknowledgment}

We would like to thank the Leverhulme Trust (studentship to FR, F/00 134/CL) and the Engineering and Physical Sciences Research Council (PDRA funding to LB, EP/K001183/1; Advanced Research Fellowship to TDS, EP/E052789/1) for supporting this work. We would also like to acknowledge the EPSRC UK National Mass Spectrometry Facility at Swansea University for analysis of some of the compounds prepared in this work.

\section{Supporting Information}

YES (this text will be updated with links prior to publication)

\section{Primary Data}

NO (this text will be deleted prior to publication)

\section{References and Notes}

(1) Current address: Dr Filippo Rota, Principal Scientist, Abcam, Unit 3, Avon Riverside Estate, Victoria Rd, Bristol BS11 9DB.

(2) (a) K. Mashima, K.-H. Kusano, N. Sato, Y.-I. Matsumura, K. Nozaki, H. Kumobayashi, N. Sayo, Y. Hori, T. Ishizaki, J. Org. Chem. 1994, 59, 3064; (b) S. Itsuno, K. Ito, A. Hirao, S. Nakahama, J. Chem. Soc., Chem. Commun. 1983, 469.

(3) (a) E. Fernández-Mateos, B. Maciá, M. Yus, Adv. Synth. Catal. 2013 355, 1249; (b) D. Seebach, D. A. Plattner, A. K. Beck, Y. M. Wang, D. Hunziker, W. Petter, Helv. Chim. Acta 1992, 75, 2171; (c) M. Ishizaki, K.-I. Fujita, M. Shimamoto, O. Hoshino, Tetrahedron: Asymmetry 1994, 5, 411; (d) Z. Dai, C. Zhu, M. Yang, Y. Zheng, Y. Pan, Tetrahedron: Asymmetry 2005, 16, 605; (e) H. C. Brown, P. K. Jadhav, J. Am. Chem. Soc. 1983, 105, 2092.

(4) (a) M. E. Abbasov, D. Romo, Nat. Prod. Rep. 2014, 31, 1318; (b) U. Scheffler, R. Mahrwald, Chem. Eur. J. 2013, 19, 14346; (c) S. Mennino, A. Lattanzi, Chem. Commun. 2013, 49, 3821; (d) J. Alemán, S. Cabrera, Chem. Soc. Rev. 2013, 42, 774; (e) C. M. R. Volla, I. Atodiresei, M. Rueping, Chem. Rev. 2014, 114, 2390.

(5) (a) B. List, R. A. Lerner, C. F. Barbas, III, J. Am. Chem. Soc. 2000, 122, 2395; (b) A. B. Northrup, D. W. C. MacMillan, J. Am. Chem. Soc. 2002, 124, 6798; (c) T. D. Beeson, D. W. C. MacMillan, J. Am. Chem. Soc. 2005, 127, 8826; (d) A. J. A. Cobb, D. M. Shaw, S. V. Ley, Synlett 2004, 558; (e) Y. Yamamoto, N. Momiyama, H. Yamamoto, J. Am. Chem. Soc. 2004, 126, 5962.

(6) a) Y. Hayashi, H. Gotoh, T. Hayashi, M. Shoji, Angew. Chem. Int. Ed. 2005, 44, 4212; (b) J. Franzén, M. Marigo, D. Fielenbach, T. C. Wabnitz, A. Kjærsgaard, K. A. Jørgensen, J. Am. Chem. Soc. 2005, $127,18296$.

(7) (a) D. D. Steiner, N. Mase, C. F. Barbas, III., Angew. Chem., Int. Ed. 2005, 44, 3706; (b) M. Marigo, T. Schulte, J. Franzen, K. A. Jørgensen, J. Am. Chem. Soc. 2005, 127, 15710.

(8) (a) M. Marigo, T. C. Wabnitz, D. Fielenbach, K. A. Jørgensen, Angew. Chem., Int. Ed. 2005, 44, 794; (b) A. Armstrong, L. Challinor, J. H. Moir, Angew. Chem. Int. Ed. 2007, 46, 5369; (c) A. Armstrong, N. Deacon, C. Donald, Synlett 2011, 2347.

(9) (a) M. D. Brown, G. H. Whitham, J. Chem. Soc., Perkin Trans. I 1988, 817; (b) M. Watanabe, M. Komota, M. Nishimura, S. Araki and Y. Butsugan, J. Chem. Soc., Perkin Trans. I 1993, 2193; (c) D. Enders, T. Schäfer, O. Piva, A. Zamponi, Tetrahedron 1994, 50, 3349; (d) D. Enders, O. Piva, F. Burkamp, Tetrahedron 1996, 52, 2893.

(10) R. Dubey, N. W. Polaske, G. S. Nichol, B. Olenyuk, Tetrahedron Lett. 2009, 50, 4310.

(11) (a) J. A. Dale, D. A. Dull, H. S. Mosher, J. Org. Chem. 1969, 34, 2543; (b) J. A. Dale, H. S. Mosher, J. Am. Chem. Soc. 1973, 95, 512; (c) G. R. Sullivan, J. A. Dale, H. S. Mosher, J. Org. Chem. 1973, 38, 2143.
(12) General procedure for preparation of $\boldsymbol{\beta}$-hydroxysulfides 5: A solution of aldehyde ( $1 \mathrm{eq})$ and catalyst 2 (0.1 eq) was stirred in toluene $(1.3 \mathrm{M})$ for $15 \mathrm{~min}$. A solution of sulfenyltriazole 3 (1.3 eq) in toluene $(1.6 \mathrm{M})$ was added dropwise and the resulting mixture was stirred under argon at RT for $24 \mathrm{hr}$. The reaction mixture was then quickly sucked under vacuum through a prewet (toluene) pad of silica ( $1.5 \mathrm{~g}$ per $100 \mathrm{mg}$ of aldehyde) and washed with toluene ( $10 \mathrm{ml}$ per $100 \mathrm{mg}$ of aldehyde). The filtrate was added dropwise to a solution of the organometallic reagent (3-4 eq) cooled to $-78^{\circ} \mathrm{C}$ (for Li reagents) or $-10^{\circ} \mathrm{C}$ (for Grignard reagents). The reaction was monitored by TLC and stirred until all the intermediate $\alpha$-sulfenylaldehyde was consumed. The reaction was then quenched with sat $\mathrm{NH}_{4} \mathrm{Cl}$, and partitioned between water and $\mathrm{Et}_{2} \mathrm{O}$. The aqueous layer was extracted with $\mathrm{Et}_{2} \mathrm{O}$ and the combined organic layers were washed with brine, dried over $\mathrm{MgSO}_{4}$, filtered and evaporated to dryness. The crude $\beta$-hydroxysulfide was purified by column chromatography (Pet/Et $\left.{ }_{2} \mathrm{O}\right)$. (2R,3S)-3-(Phenylthio)octan-2-ol (5a): $[a]_{D}^{25}-4.2$ (c. 1.0, $\left.\mathrm{CHCl}_{3}\right) ; v_{\max }\left(\mathrm{film} / \mathrm{cm}^{-1}\right)$ 3414, 3060, 2959, 2929, 2858, 1584, 1466, 1439, 1279, 1139. Isolated as a 91:9 mixture of diastereoisomers; major isomer $\delta_{\mathrm{H}}\left(600 \mathrm{MHz}, \mathrm{CDCl}_{3}\right) 0.88(3 \mathrm{H}, \mathrm{t}, J$ $\left.=6.8, \mathrm{CH}_{2} \mathrm{CH}_{3}\right), 1.19\left(3 \mathrm{H}, \mathrm{d}, J=6.4, \mathrm{CHCH}_{3}\right), 1.27-1.71(8 \mathrm{H}, \mathrm{m}, 4 \times$ $\left.\mathrm{CH}_{2}\right), 2.33(1 \mathrm{H}$, br s, OH), $3.16(1 \mathrm{H}, \mathrm{ddd}, J=9.4,5.8,3.2, \mathrm{SCH})$, $3.89(1 \mathrm{H}, \mathrm{qd}, J=6.4,3.2, \mathrm{CHOH}), 7.22-7.30(3 \mathrm{H}, \mathrm{m}, 3 \times \mathrm{ArH}), 7.44$ $(2 \mathrm{H}, \mathrm{d}, J=7.7,2 \times \mathrm{Ar} H) ; \delta_{\mathrm{C}}\left(150 \mathrm{MHz}, \mathrm{CDCl}_{3}\right) 14.2,19.1,22.6$, 27.5, 30.1, 31.8, 58.7, 68.3, 127.1, 129.2, 132.0, 135.5; minor isomer $\delta_{\mathrm{H}}\left(600 \mathrm{MHz}, \mathrm{CDCl}_{3}\right) 0.88\left(3 \mathrm{H}, \mathrm{t}, J=6.8, \mathrm{CH}_{2} \mathrm{CH}_{3}\right), 1.25(3 \mathrm{H}, \mathrm{d}, J=$ 6.1, $\left.\mathrm{CHCH}_{3}\right), 1.27-1.71\left(8 \mathrm{H}, \mathrm{m}, 4 \times \mathrm{CH}_{2}\right), 2.91(1 \mathrm{H}, \mathrm{ddd}, J=9.6,6.5$, 3.2, $\mathrm{SCH}), 3.72(1 \mathrm{H}, \mathrm{dq}, J=6.5,6.1, \mathrm{CHOH}), 7.22-7.30(3 \mathrm{H}, \mathrm{m}, 3 \times$ $\mathrm{Ar} H), 7.44(2 \mathrm{H}, \mathrm{d}, J=7.7,2 \times \mathrm{Ar} H) ; \delta_{\mathrm{C}}\left(150 \mathrm{MHz}, \mathrm{CDCl}_{3}\right) 14.2$, 20.2, 22.7, 27.0, 30.1, 31.1, 59.3, 68.3, 127.3, 129.1, 132.5, 135.5, Found (EI): $[\mathrm{M}]^{+} 238.13884, \mathrm{C}_{14} \mathrm{H}_{22} \mathrm{OS}$ requires 238.13859 .

(13) The absolute stereochemistry of the alcohol $\mathbf{5 1}$ was determined by NMR analysis of the Mosher's ester derivatives (see Ref 11). Full experimental details are provided in the supporting information.

(14) D. Hou, T. L. Lowary, Org. Lett. 2007, 9, 4487.

(15) General procedure for preparation of alcohols 6: A solution of $\beta$-hydroxysulfide ( $1 \mathrm{mmol}$ ) and Raney-Ni (2 g) in EtOH (0.05 M) was stirred at reflux for 2-4 hours. The mixture was cooled to RT and filtered through a pad of Celite $®$. The filtrate was evaporated to dryness to afford the alcohol. (R)-Octan-2-ol (6a): $[a]_{D}^{25}-5.4$ (c. 1.0, $\left.\mathrm{CHCl}_{3}\right) ; v_{\max }\left(\mathrm{film} / \mathrm{cm}^{-1}\right) 3339,2960,2927,2857,1462$, $1373,1279,1177,1141,1115 ; \delta_{\mathrm{H}}\left(400 \mathrm{MHz}, \mathrm{CDCl}_{3}\right) 0.91(3 \mathrm{H}, \mathrm{t}, J=$ 6.9, $\left.\mathrm{CH}_{2} \mathrm{CH}_{3}\right), 1.21\left(3 \mathrm{H}, \mathrm{d}, J=6.1, \mathrm{CHCH}_{3}\right), 1.27-1.51(10 \mathrm{H}, \mathrm{m}, 5 \times$ $\left.\mathrm{CH}_{2}\right), 3.81(1 \mathrm{H}, \mathrm{m}, \mathrm{CHOH}) ; \delta \mathrm{c}\left(100 \mathrm{MHz}, \mathrm{CDCl}_{3}\right)$ 14.1, 22.6, 23.5, 25.7, 29.3, 31.8, 39.4, 68.2. These spectroscopic data are in agreement with those reported previously: M. Maywald, A. Pfaltz, Synthesis, 2009, 3654-3660.

(16) The diastereomeric $\beta$-hydroxysulfides were not readily separable. Thus, the enantiomeric ratio of the alcohol $\mathbf{6}$ was calculated from the enantiopurity of the intermediate $\alpha$-sulfidoaldehyde (determined by reducing a sample to the primary alcohol 4) and the diastereomeric ratio of the purified $\beta$-hydroxysulfide $\mathbf{5}$ used in the desulfurization reaction. Please see supporting information for further details.

(17) S. L. Schreiber, J. Reagan, Tetrahedron Lett. 1986, 27, 2945; separation of derivatives of $\mathbf{5 e}$ via chiral HPLC was also unsuccessful.

(18) S.-K. Kang, D.-Y. Kim, R.-K. Hong, P.-S. Ho, Synth. Commun. 1996 26, 3225 .

(19) (a) V. K. Aggarwal, C. L Winn, Acc. Chem. Res. 2004, 37, 611; (b) Z.X. Wang, Y. Tu, M. Frohn, J.-R. Zhang, Y. Shi, J. Am. Chem. Soc. 1997, 119, 11224; (c) W. Zhang, J. L. Loebach, S. R. Wilson, E. N. Jacobsen, J. Am. Chem. Soc. 1990, 112, 2801. 
